\title{
Effectiveness of the Polar Code Training of Cruise Liner Crew for Evacuation in the Arctic and Antarctic
}

\author{
M.R. Chaure \& O.T. Gudmestad \\ Western Norway University of Applied Sciences, Haugesund, Norway
}

\begin{abstract}
In the past decades, we have seen a prolific increase in Polar Cruise Tourism, and thereby, more humans are able to visit the Polar Regions. As a result of this, the IMO implemented the Polar Code in 2017 to better prepare seafarers in polar waters in order to ensure maritime safety. Several researches have been carrying out work, after the Polar Code came into force, to evaluate its realization concerning the harsh climatic conditions of the Arctic and Antarctic. Based on the Polar Code requirements, the crew's preparedness for evacuation and survival in negative temperatures due to remoteness, is somewhat ambiguous. Also, the use of safety equipment in the polar climate still is in the discussion, whether sufficient or not.

This paper investigates the cruise crew's preparedness for an evacuation in the Arctic and Antarctic, according to the Polar Code. Here, gaps in the existing Polar Code Basic and Advanced Training modules were identified with respect to evacuation needs. Questionnaires and interviews were used as the research method to evaluate the insights of the potential target audiences. The study findings were analyzed and reveal the Polar Code's ineffectiveness with respect to educating the cruise crew for an evacuation, along with the lack of requirement to passenger survival training.

This study recommends specific evacuation training for all the cruise crew members based on the actual needs and, subsequently, the need for improvement in the Polar Code training modules. It also proposes survival training modules for cruise passengers to be developed, for evacuation of a vessel in the Arctic and Antarctic.
\end{abstract}

\section{INTRODUCTION}

Since the past decades, the Earth's average temperature is rising alarmingly. Consequently, the world has been experiencing global warming in terms of natural disasters and melting glaciers in the north and south pole regions of the planet. Sea ice in the Arctic and Antarctic has been melting dramatically as observed in the past few years, which raises concerns regarding survival for many of its inhabitants. Many researchers are working on measures to reduce the carbon footprint and stop its impact on climate change. The approach of the Maritime Industries towards climate change has both pros and cons in terms of increased shipping business profit and increased threat to the unspoiled polar region. Some consider melting ice in the polar region as an opportunity for boosting their economy by expanding their business further in the northern seafront, as there are reserves of hidden natural resources under the polar seabed. One of the Industries which benefits with the ice-free passage in the Arctic and Antarctic, offering voyages longer periods of the year is the 'Cruise Industry'. The Cruise Industry has thereby attracted hundreds of passengers who can afford to fulfill their bucket-list, by introducing opulent packages in the unique and mesmerizing polar region. 
In the past decades, we have seen a prolific increase in Polar Cruise Tourism and humans are able to make a mark on charismatic creation.

The increase in cruise traffic, however, adds increased challenges and risks associated with maritime safety due to adverse climatic conditions and thousands of human lives involved. Several challenges that make sailing at both polar regions dangerous and unfavorable where passenger safety is at risk in the remoteness. In particular, unpredictable weather with sudden changes will lead to detrimental effects on the usage of Life-Saving Appliances (LSA) in case of an emergency. The accelerating cruise industry is planning voyages where a large number of passengers involved is lacking maritime safety, 'Are we prepared for large mass evacuation in an unforeseen scenario or emergency?' Some of the past incidents and near disasters unveil how lack of preparedness influences maritime safety.

At the advents of Climate Change, IMO implemented the Polar Code on 1st January 2017 for ships operating in Polar Waters. The Standards of Training, Certification, and Watchkeeping (STCW) Chapter V [5] and the Polar Code - Chapter 12 describe the requirements to training, considering the international convention on the standards of training and certification of seafarers [2]. According to this, masters, chief mates, and officers in charge of a navigational watch in open water must have certification of Basic and/or Advanced Polar Code training [2]. IMO Canada provides guidelines for the Instructors of the course as per the requirements of the Polar Code [3].

The Polar Code enforcement has led to greater maritime safety to counteract the challenges with weather and remoteness; however, the practicality of the training of the crew regarding evacuation has not been discussed. This question the effectiveness of the Polar Code regarding training of crews relating to evacuation. This paper focuses on the preparedness of cruise crews for evacuation and survival in relation to implementation of the Polar Code. In this paper we study how the Polar Code Basic and Advanced Training modules offered by various authorized institutes cover the evacuation training needs and analyze gaps along with identifying training needs for passengers.

\section{METHOD}

To investigate the gap in the existing Polar Code training, qualitative and quantitative data were collected using the Interview and Survey Questionnaire methodology. The participants were selected based on a purposive sampling method that served the purpose of this study. Accordingly, the respondents identified were among the Crews, the Training Institutes and the Passengers categories. The questionnaires were divided into three groups and distributed among the respective target audiences.

The survey target groups were identified based on the following factors:

1 Geographical Areas: Arctic and Antarctic (Polar Regions)
2 Crews experienced in Polar Cruise shipping and certified with Polar Code Basic or Advanced Training modules.

3 Passengers experienced with Polar Cruising in the Arctic or Antarctic.

4 Authorized Training Institutes for Polar Code Training

Questionnaire (Survey): A total of 16 questions (both open and close-ended) were formulated for the individual target groups [6].

Total responses received for the survey were 17 and 4 telephonic interviews were conducted.

The collected data were analyzed based on Hypothesis Testing. During hypothesis testing, a null $\mathrm{HO}$ hypothesis and an alternative Ha hypothesis are proposed. The null hypothesis is proved or disapproved based on the sample data collected in the survey, supported by reliable insights from qualitative interviews.

The hypothesis to prove or disapprove were formulated as follows:

- Null Hypothesis (H0): Polar Code training of crews is effective during an evacuation.

- Alternative Hypothesis (Ha): Polar Code training of crews is not effective during an evacuation.

\section{DATA ANALYSIS}

The survey questions were categorized to be relevant for the target groups. The analysis of data collected was then done; if the response supported the Polar Code training concerning evacuation, then the response supported the null hypothesis else favored the alternative hypothesis.

\section{$3.1 \operatorname{Set} A$}

Polar Code training effectiveness with regards to crews' competence during evacuation.

The collected data from the survey include the findings with respect to Polar Code Training effectiveness in preparing the crews for emergency evacuation as asked in question - Q1 of the survey questionnaire to Institutes and Crew target groups.

The total responses from the Crew and Institutes are 12 [6]. The crews and the training institutes' responses play a crucial role in evaluating the effectiveness pertaining to evacuation, because they are directly involved in the actual Polar Code training. The crews are the ones who will gain expertise from the authorized training centers depending on how institutes have designed and offered that course, considering its focus being mainly on evacuation preparedness. 


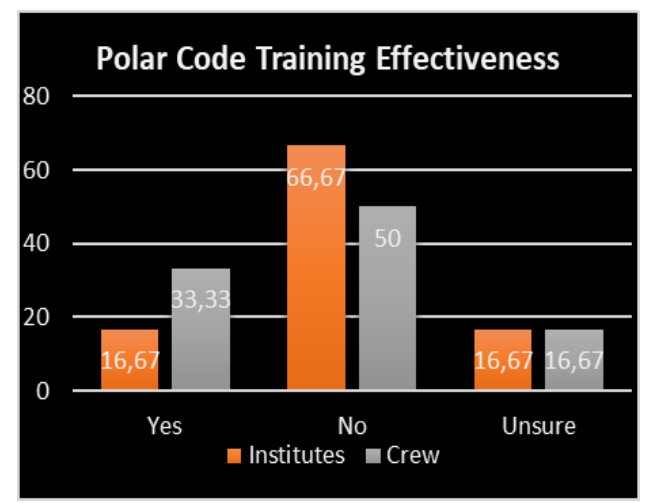

Figure 1. Statistical Data Analysis for Polar Code Training [6]

Above data in Figure 1, indicates that more than $66 \%$ of training institutes and $50 \%$ of crews' responses considered the Polar Code not being effective in terms of evacuation training. This reflects the Polar Code training effectiveness with respect to crew and institutes which favors the alternative hypothesis. Furthermore, Set B, C, and D give support to these findings, where responses are analyzed based on the outcomes of the training that is being tested when crews perform their duties onboard, based on the target group's experiences.

\subsection{Set $B$}

To identify the competence level of the crew, relevant (A) questions (Figure 2) were asked in the survey. The Training Institutes and the Crew target groups were asked "patterned questions" to find out whether the training fulfils the actual requirements during an evacuation, that reflects their real situations.

The questions were phrased such that they will answer the competence level, where A is "Applicable".

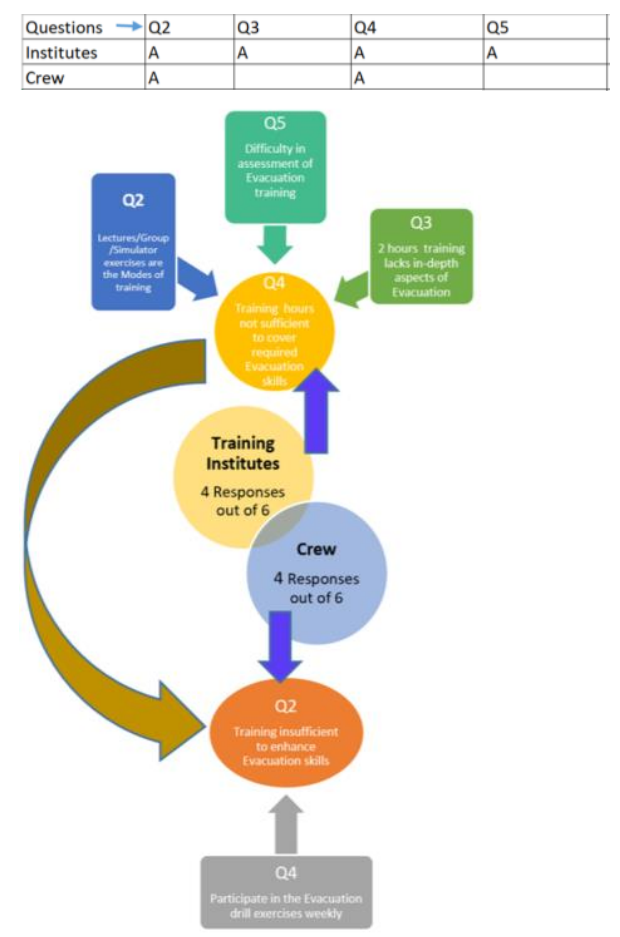

Figure 2. Responses of "Patterned Questions" for Crew Competence Analysis based on Polar Code Training [6]
In the case of the Training Institutes, they were asked a question relevant to different modes of training (question 2, Q2); and questions regarding the assigned hours to cover the evacuation training and whether the time assigned is sufficient (questions 3 \& 4, Q3 \& Q4). Consequently, the assessment of the crews who had participated in the Polar Code training was analyzed in question 5 (Q5), which would indicate the crew's competence in performing the task. We observed from the institute's responses that they do not follow any standardized training method, and some are lagging assessment considering these challenges. Also, from the survey responses, it reflects that the training for evacuation is insufficient to cover in-depth aspects of the evacuation.

The survey data shown in Figure 2, demonstrates the relation between the opinions of the institutes and the answers to the questions when asked to the Crew group. The crew were asked about how often they participate in an evacuation drill exercises in question 4 (Q4). The crew were, furthermore, asked about the improvement in their skills when attending Polar Code training offered by different institutes in question 2 (Q2). As shown in the Training institute responses in Figure 2, evacuation training is missing real intensity and that is reflected in the responses from the Crew, wherein the data indicates that Polar Code training is not helping to improve their skills pertaining to evacuation.

Set C and D: Furthermore, dependent questions in Sets $C$ and D were asked to each target group to cover the opinions about limitations and possible improvements in the Polar Code training. The answers demonstrate the challenges and suggested improvements of Polar Code training concerning evacuation as shown in Figures $3 \& 4$. Thus, the survey questions cover the holistic approach to identify the gaps in the existing Basic and Advanced Polar Code training modules.

\subsection{Set C}

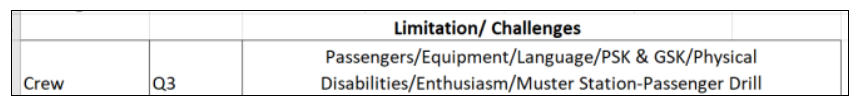

Figure 3. Dependent question - Limitation / Challenges for Polar Code Training [6]

\section{$3.4 \operatorname{Set} D$}

\begin{tabular}{|l|l|c|}
\hline \multicolumn{2}{|c|}{ Improvement Suggestions } \\
\hline Crew & Q5 & Equipment/guidelines/official/evacuation rules/passenger handling \\
\hline Passenger & Q1 & Muster Drill Helpful \\
\hline & Q2 & Missing Awareness about PSK \& GSK, LSA, LifeVest not suitable for Kids \\
& Q3 & $\begin{array}{c}\text { Brochure of Training guideliness with Safety Procedure via email before } \\
\text { trip }\end{array}$ \\
\hline Institutes & Q6 & Passenger Safety Training not offered \\
\hline & Q7 & Prilminary Evacuation Exercises/LSA and cold climate awareness/ \\
& Realistic training in groups \\
\hline & L8 & LSA training not required \\
\hline
\end{tabular}

Figure 4. Dependent questions - Improvement Suggestions for Polar Code Training [6] 


\section{STATISTICAL METHOD FOR HYPOTHESIS TESTING: FISHER'S EXACT TEST}

The sample size of the population is small; hence the Fisher's Exact Test is used to evaluate whether the null hypothesis or the alternative hypothesis is valid.

In this test, based on the $2 \times 2$ contingency matrix shown in Table 1 , the probability value, the p-value, is calculated. The significance level $(\alpha)$ of the null hypothesis is tested as follows [1]:

If the $\mathrm{p}$-value is smaller than 0.05 ( $\alpha$ value), then the null hypothesis is rejected. Thus, the alternative hypothesis is accepted. This means that a $5 \%$ error is sufficient to decide whether the null hypothesis is rejected. If the value of $\mathrm{p}<\alpha$, the result is statistically significant.

Considering this, the p-value calculated using an online Fisher's Exact Test Calculator based on 'yes/no' responses from the Training Institutes and the Crew target group (as per Figure 5 and Table 1) is found to be: Exact two-tailed probability (p): 0.03 , thus $p<0.05$ [7].

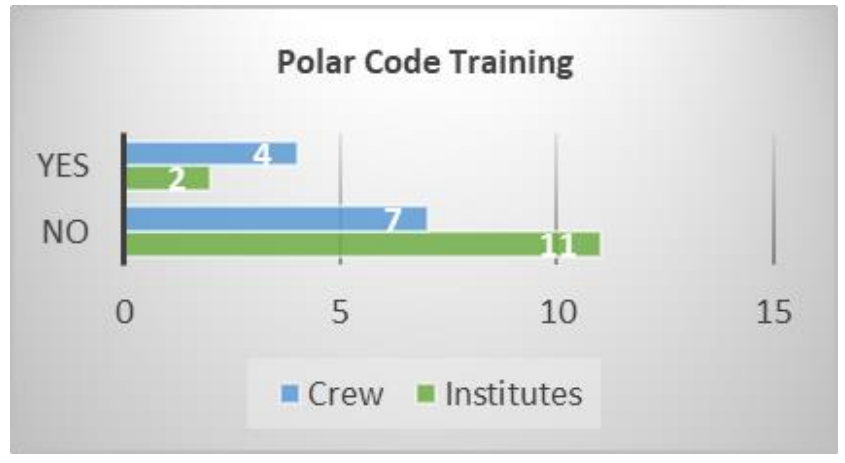

Figure 5. Responses for Polar Code Training based on questions (Training Institutes Q1, Q4 \& Q5, and Crew Q1 \& Q2) [6]

Table 1. Fisher's Exact Test 2x2 Contingency matrix [7]

\begin{tabular}{|c|c|c|c|c|c|c|}
\hline \multicolumn{4}{|c|}{ Responses } & \multicolumn{2}{|c|}{ No } & Yes \\
\hline \multicolumn{4}{|c|}{ Training Institutes (X) } & \multicolumn{2}{|c|}{11} & 2 \\
\hline \multicolumn{4}{|c|}{ Crew $(\mathrm{Y})$} & \multicolumn{2}{|c|}{7} & 4 \\
\hline \multicolumn{4}{|c|}{$\bar{x}$} & \multirow{3}{*}{$\begin{array}{c}\text { Totals } \\
13 \\
11\end{array}$} & & \\
\hline & & 0 & 1 & & \multicolumn{2}{|c|}{ Fisher Exact Probability Test: } \\
\hline \multirow[t]{2}{*}{ Y } & $\frac{1}{n}$ & 11 & 2 & & & one-tailed 0.021368959483106367 \\
\hline & tals & 15 & 9 & 24 & & two-tailed 0.0327433032709646 \\
\hline
\end{tabular}

This shows that the Probability value (p-value) is smaller than 0.05 ( $\alpha$ value) and hence (according to the Fisher's Exact Test), the null hypothesis is rejected. The alternative hypothesis is accepted, and the result is statistically significant based on the Fisher's exact test [1].

The responses from the crew and training institute groups favor the alternative hypothesis concerning to the Polar Code training effectiveness discussed in Set A. Based on the data analysis with respect to the questionnaire categorized into patterns (Figure 2) and Fisher's Exact test (Table 1), it shows that the null hypothesis fails, and the alternative hypothesis is proven. The dependent questions explained in Set B shows the reasoning, where the pattern result indicates the crews and training institutes target groups' opinions.

Furthermore, the interview comments from focused target groups validate the finding of the data analysis from the survey result:

1 Interviewed Crew members mentioned the inadequacy of Polar Code training, as it doesn't provide enough awareness about safety procedures needed at the time of the evacuation onto the ice. They highlighted the need for proper instruction for immersion suits handling, no one was aware about the Group Survival Kit (the GSK) and how to use it. They claimed that training mostly focuses on ice navigation and nothing about evacuation details. They mentioned that the cruise management was unaware about Polar Code's applicability.

2 The Institutes' offered training mostly focuses on ice navigation, communication, etc., with just two hours of theoretical lessons related to evacuation, which hardly covers the necessary details as more practical understanding is required.

3 From the passengers' safety point of view, the crew highlighted the need for basic awareness training for passengers as shown in Set D above. The interviewed passenger also recommended training but was unsure how the training should be carried out. Crew members and Passengers highlighted the challenges of elderly handling immersion suits.

A document review of the training brochures from the training institutes highlighted the eligibility requirement for the Advanced module of Polar Code training. To be eligible for the Advanced module, one should have two months of sea-going experience in polar waters. Also, the Basic and Advanced training modules mention Crew Preparation as well as working conditions and safety, but it is uncertain if two hours of training suffices the actual needs of the evacuation preparedness.

\section{RESULTS}

The results from the quantitative and qualitative data analysis show that the Polar Code Basic and Advanced training modules are not satisfying the real needs for evacuation preparation. The gaps in the existing training modules are identified based on the hypothesis testing and the alternative hypothesis is proven. It exhibits that at present; we are not meeting the real requirements of evacuation needs for harsh climate, human behavior, and applicability of safety equipment by the training modules. The cruise liner management are complying with the functional requirements of the Polar Code but not what is needed concerning to cover the real scenarios in the polar waters.

The gap identified in the existing training modules from this study should be viewed as a follow-up of the SARex2 findings [4]. According to the SARex2 exercise, risk analysis findings highlighted the need for training for both Crews and Passengers in order to evacuate safely [4]. As mentioned in the SARex2 report by a person representing a Classification Society, training should not focus only on masters, 
chief mates, and officers in charge of navigation but also on engineers and first officers who are in addition to normal duties responsible for evacuation in case of emergency [4]. Data analysis result and the SARex2 findings [4] call for in-depth training of all the crew, in particular the designated officers involved in possible evacuation, along with passenger training.

\section{CONCLUSIONS}

The Polar Code Basic and the Advanced training modules for crew training, when considering evacuation, should not be limited to a theoretical approach. When the crew members reflect on the applicability of the learning from the virtual training into real scenarios, the assessment should confirm the effectiveness of the Polar Code training in an actual situation.

These are the findings which need to be taken care of in order to move forward for better human and maritime safety concerning crew preparedness for an evacuation:

- Crew Training should not be limited to masters, chief mates, and officers in charge of navigational watch. However, training should go beyond these groups, by training all the crew members present at the voyage, to prepare for any unforeseen situations. Specialized training needs to be arranged by individual cruise liners to train their crew members specific on 'Evacuation'. It will help crew members to be specific about how to respond in quickly changeable weather situations in the Arctic/Antarctic. Cruise management should effectively plan and develop guidelines and procedures for the Polar Code training concerning evacuation.

- It is necessary to develop a survival training module for cruise passengers concerning use of safety equipment for muster drill, and awareness about cold-weather survival. The training needs to be arranged either by the private institutes who are responsible for crew training or as mandatory training when passengers book their trips with cruise liner companies.

- Training Institutes need to plan in-depth training concerning evacuation needs, beyond theoretical lessons. They should focus their training module considering practical aspects, based on the changing and harsh climatic conditions, focusing on real scenarios.

- IMO Polar Code training regarding Basic and Advanced modules needs to include the actual requirements during an evacuation. According to the identified findings for crew preparedness in this research, the applicability should be related to Cruise Ships and training guidelines should be updated. The training should focus on essential needs that cover practical evacuation skills and handling of Personal and Group Survival Kits (PSK \& GSK) and Life-Saving Appliances usage.

\section{FURTHER WORK}

The study concluded with recommending in-depth training of the entire Crew involved in the muster, along with additional survival training requirements for Passengers. Below is a possible scope in terms of Passenger Training:

- E-training Module

Necessary safety guidelines, procedures, and equipment awareness should be provided with the help of a short E-training module that serves the purpose of evacuation awareness and would mitigate the risk of misunderstandings due to the language barriers.

The E-training should cover the usage of PSK and GSK; how, when, and why these are required. Also, the training should provide guidelines for the access to muster stations and do's and don'ts with respect to cold climate (Arctic/Antarctic).

Passengers should have an interactive training module, where they can ask questions if they are uncertain. This training module should be part of their trip and should represent a mandatory requirement to be fulfilled prior to boarding any expedition cruises to the polar regions. Cruise liners can collaborate with training institutes to design a short training module or build such inhouse with reference to company policy.

- Additional information needed prior to boarding the cruise.

Cruise line management needs to make sure about the medical fitness of the passengers; they can ask for medical fitness certificates before confirming seats to any of the Polar Expedition Cruises.

Also, it came into notice during the research that many passengers overlook the actual content in the cruise liners' brochures, and they book Cruises where often no dedicated language assistance is available. To avoid this, while booking, cruise liner companies can ask passengers for their language and plan to assign dedicated Crew to support the emergency requirements accordingly.

- Safety Leaflet

All the necessary safety procedures/guidelines, and details of cruise muster stations should be printed in a Safety Leaflet with an utmost visual understandable mode in a leaflet form. At the time of boarding, a crew member should distribute this safety leaflet to all passengers on board: This would ensure that all passengers be aware about possible measures needed to be taken in case of an emergency evacuation, even if they miss to remember muster training details.

\section{REFERENCES}

[1] Agresti, A \& Franklin, C, (2013), Statistics -The Art and Science of Learning from Data, pp - 514, 593, Pearson.

[2] International Maritime Organization IMO (2017), INTERNATIONAL CODE FOR SHIPS OPERATING IN POLAR WATERS (POLAR CODE), Retrieved from http://www.imo.org/en/MediaCentre/HotTopics/polar/D ocuments/POLAR\%20CODE\%20TEXT\%20AS\%20ADOP TED.pdf

[3] Master Mariner, CANADA (2017), Model Courses, Retrieved from BASIC TRAINING FOR SHIPS 
OPERATING IN POLAR WATERS,

https://www.transportstyrelsen.se/contentassets/8133299 348c942509e1ae60c39eef787/4-wp6annex1.pdf

[4] Solberg, K.E., Gudmestad, O.T. and Skjærseth, (2017) SARex2: Surviving a maritime incident in cold climate conditions. Exercise report. University of Stavanger. Retrieved from https://uis.brage.unit.no/uisxmlui/handle/11250/2468805

[5] International Maritime Organization IMO, STCW (1978), International Convention on Standards of Training, Certification and Watchkeeping for Seafarers (STCW),
Retrieved

from http://www.imo.org/en/About/Conventions/ListOfConv entions/Pages/International-Convention-on-Standardsof-Training,-Certification-and-Watchkeeping-forSeafarers-(STCW).aspx

[6] Survey Monkey. (2020), Master Thesis Survey Link, Retrieved from https://www.surveymonkey.com/ home/?ut_source=header

[7] Vassarstats, 2020, Fisher Exact Test Calculator, Retrieved from http://vassarstats.net/tab2x2.html 